\title{
EDITORIAL
}

\section{Why teach science?}

The answer to the rhetorical question above will seem obvious to many. Science is considered to be the driving force behind all modern technological developments, which bring with them improved health, higher living standards and economic growth resulting in the satisfaction of many basic human needs including cultural and social needs.

While all of the above may be accepted, there is another dimension to the answer, one that is not generally recognised and addressed by the way we teach science; the importance of disseminating throughout society the scientific temper of mind. India is perhaps unique in having a clause in its constitution making it the duty of every citizen 'to develop scientific temper, humanism and the spirit of inquiry and reform'.

The search for scientific knowledge rests on the belief that reality is objective and comprehensible. In teaching science, two aspects are generally recognised. Firstly, scientific knowledge consisting of experimental observations (so called 'scientific facts') and the theories that explain, rationalise and broadly makes sense of the observations. Secondly, the processes which enable the generation of this knowledge. Philosophers of science argue that there is no single process or method called 'The Scientific Method'. The linear process usually taught in schools; observation, hypothesis, prediction and experiment eventually leading to a theory is useful only for illustrating some of the principles involved in the generation of scientific knowledge.
Scientific temper of mind needs to be distinguished from the application of methods for the generation of scientific knowledge. The eminent British philosopher and mathematician Bertrand Russel identifies the kernel of the scientific outlook as 'the refusal to regard our own desires, tastes and interest as affording a key to the understanding of the world'. An individual with a scientific temper of mind will be imbued with the ethical values embedded in the pursuit of scientific knowledge, particularly, fidelity to the truth, and open-mindedness. A society in which the scientific temper of mind is widespread will be less influenced by superstition, prejudice and pseudo-science. In its ability to look at issues objectively, it will be not susceptible to irrational propaganda which appeals to the baser human instincts. It will, on the whole, be a progressive and humane society.

Exclusively examination-oriented science education that takes place in an intensely competitive environment in Sri Lanka is not conducive for students to develop a scientific temper of mind. Too often, science is taught as a set of rules and principles to learn and apply. There is a need to improve this aspect of science education. The scientific temper of mind will arise naturally in students when they see science as an extraordinarily exciting journey of discovery undertaken by mankind towards understanding the world we live in.

Ajit Abeysekera 